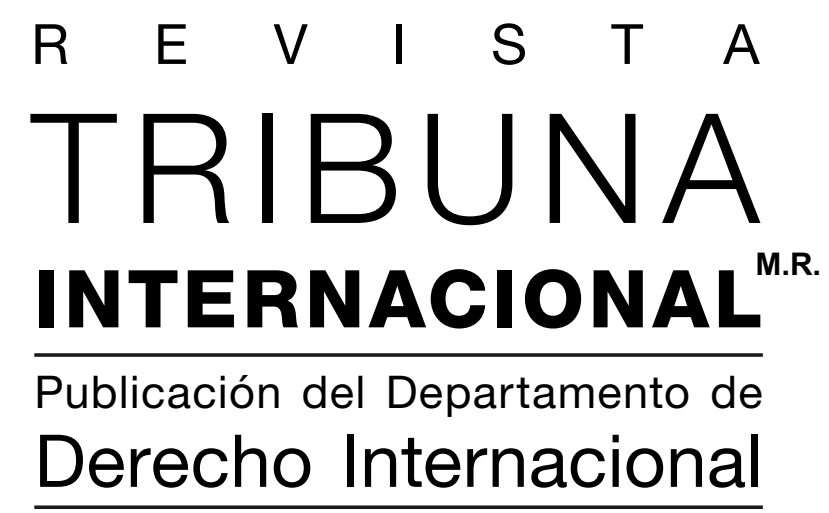

Volumen $4 / N^{\circ} 7 / 2015$

DERELTAD DE

UNIVERSIDAD DE CHILE 


\section{Rector de la Universidad de Chile}

Ennio Vivaldi Véjar

Av. Alameda Libertador Bernardo

O’Higgins 1058, Santiago

Representante legal

Davor Harasic Yaksic

Decano de la Facultad de Derecho

Universidad de Chile

Director del Departamento de

Derecho Internacional

Edmundo Vargas Carreño

Director de la Revista Tribuna

Internacional

Mario Ramírez Necochea

Editor General de la Revista Tribuna

Internacional

Luis Valentín Ferrada Walker

\section{Comité Editorial}

Íñigo Álvarez Gálvez (Universidad de Chile, Chile)

Gonzalo Aguilar (Universidad de Talca, Chile)

José Carlos Fernández Rosas

(Universidad Complutense de Madrid,

España)

Claudio Grossman (American

University, EE.UU)

Mattias Kumm (New York University,

EE.UU)

Hugo Llanos (Universidad Central, Chile)

Cecilia Medina (Universidad Diego

Portales, Chile)

Elina Mereminskaya (Universidad de Chile, Chile)

Mónica Pinto (Universidad de Buenos Aires, Argentina)

\section{Revista Tribuna Internacional M.R.}

Publicación del Departamento de Derecho Internacional de la Facultad de Derecho de la Universidad de Chile. $\mathrm{Su}$ objetivo es fomentar la reflexión, el debate, el análisis y la comunicación sobre el derecho internacional en forma pluralista y con rigor científico. Se publica cada semestre en los meses de junio y diciembre mediante convocatoria abierta a la publicación de artículos y monografías inéditos, comentarios de jurisprudencia, recensiones y comentarios de libros, en los campos de derecho internacional público y privado, derecho internacional de los derechos humanos y relaciones internacionales, tanto en castellano como en inglés.

Volumen 4/ No 7 / 2015

www.tribunainternacional.uchile.cl

ISSN 0719-210X (versión impresa)

ISSN 0719-482X (versión en línea)

Departamento de Derecho Internacional Facultad de Derecho

Universidad de Chile

Av. Santa María 076, $4^{\circ}$ piso

Providencia, Santiago de Chile

\section{Diseńo y producción:}

Gráfica LOM

www.lom.cl

Impreso en Chile/ Printed in Chile

Se autoriza la reproducción total o parcial del contenido de la publicación, siempre que se reconozca y cite el/ la/ los/ las autor/a/es/as y la publicación, no se realicen modificaciones a la obra y no se la utilice para fines comerciales. 
Revista Tribuna Internacional

Volumen $4 \cdot \mathrm{N}^{0} 7 \cdot 2015 \bullet$ pp. $155-172$

ISSN 0719-210X (versión impresa)/ISSN 0719-482X (versión en línea)

\title{
La Antártica ante la Corte Internacional de Justicia: A 60 años de los casos Reino Unido c. Chile y Reino Unido c. Argentina ${ }^{1}$
}

\author{
Antarctica on the International Court of Justice: 60 year af- \\ ter the cases Union Kingdom v. Chile and Union Kingdom $v$. \\ Argentina
}

\section{Luis Valentín Ferrada Walker}

lvferrada@derecho.uchile.cl

Abogado, Candidato a Doctor en Derecho y Profesor del Departamento de Derecho Internacional de la Facultad de Derecho de la Universidad de Chile.

Resumen: Se analizan las demandas respecto a la soberanía sobre la Antártica presentadas por el Reino Unido ante la Corte Internacional de Justicia contra Chile y contra Argentina en 1955. Se revisan también los documentos emitidos durante la tramitación de estas causas. Los Estados demandados no estuvieron dispuestos a otorgar competencia a la Corte, motivo por el cual ambas causas fueron en definitiva retiradas de la lista sin que se resolviera sobre el fondo de la disputa. No obstante ello, parece relevante considerar estos casos para conocer los fundamentos en que los Estados implicados, y en especial el Reino Unido, basan su soberanía antártica, así como para comprender que, en definitiva, la actitud de Chile y Argentina colaboró en el proceso que culminaría pocos años más tarde con la firma del Tratado Antártico.

Palabras claves: Antártica, Corte Internacional de Justicia y soberanía antártica.

Abstract: The applications presented in relation with the sovereignty over the Antarctica by the United Kingdom on International Court of Justice against Chile and against Argentina in 1955 are analyzed. The documents delivered during the process are also revised. The defendants States were not prepared to accept the Court jurisdiction; therefore both causes were definitely retired from the list without resolve about the dispute. Nevertheless, it seems relevant to consider these cases to know the grounds on which the implicated States and specially the United Kingdom support their Antarctic sovereignty and also to understand that at the end the Chilean and Argentinian attitude helped on the process that will finish few years later with the signature of the Antarctic Treaty.

Keywords: Antarctica, International Court of Justice, Antarctic sovereignty.

1 Comentario de jurisprudencia enviado el 01.04.2015 y aceptado el 04.05.2015. 


\section{Generalidades}

Hace ya 60 ańos, el 4 de mayo de 1955, el Gobierno del Reino Unido e Irlanda del Norte interpuso ante la Corte Internacional de Justicia (CIJ) una demanda contra Chile y otra contra Argentina para que dicho tribunal resolviera respecto a la soberanía sobre ciertas islas y tierras en la Antártica². Si bien el Reino Unidos pretendió establecer como fecha de cristalización de las controversias en el caso de Chile el año 1940, cuando se fijaron los límites del Territorio Chileno Antártico, y respecto a Argentina en 1925, cuando se disputó por primera vez la supuesta soberanía británica sobre las islas Orcadas del $\mathrm{Sur}^{3}$, lo cierto es que los diferendos se remontaban a las reclamaciones, actos soberanos e intercambios diplomáticos realizados por los tres Estados al menos desde 1906 (a lo que Chile puede agregar títulos coloniales, actos del Gobierno de O'Higgins o diversos actos oficiales y manifestaciones durante el s. XIX e inicios del s. XX). Por lo demás, estas demandas deben entenderse en el contexto de una tensa relación internacional antártica en los años inmediatamente posteriores a la II Guerra Mundial. En ella no se omitió la amenaza de uso de la fuerza por parte del Reino Unido ${ }^{4}$, y ya a fines de 1947 se había manifestado la intención británica de acudir a los tribunales internacionales 5 .

2 Los documentos citados sobre esta controversia judicial se encuentran recopilados en CIJ, Antarctica Cases (United Kingdom v. Argentina; United Kingdom v. Chile): orders of March 16th, 1956; removal from the list. Pleadings, oral arguments, documents. La Haya, 1956, 114 p. Parcialmente disponible [en línea] <http://www.icj-cij.org> [consulta: 10 de junio del 2015]. Esta obra tiene una Parte I denominada "Application instituting proceedings and pleadings", donde se incluyen las respectivas demandas británicas y sus documentos fundantes; unas partes II y III, que dada la forma como concluyó este caso sólo se han considerado para efectos de mantener el formato, pero no contienen ningún antecedente; y una Parte IV, denominada "Correspondence", donde se incluyen las comunicaciones oficiales producidas a raíz de la tramitación de estos casos. En lo que sigue, y salvo que parezca necesario hacer alguna indicación distinta, los documentos y antecedentes se individualizarán por la indicación de "Application" o "Correspondence", seguido del número de página que corresponda dentro de la publicación.

Application, pp. 48 y 70 , pp. 8 y 32, respectivamente.

4 Sobre el envío a la Antártica por parte de los británicos de la fragata Snipe y del crucero Nigeria en 1948, así como de otros actos destinados a perturbar el viaje al Sexto Continente del Presidente Gabriel González Videla, vid. Garay, Cristián, y Soto, Ángel. Gabriel González Videla. No a los totalitarismos, ya sean rojos, pardos o amarillos..., Centro de Estudios Bicentenario, Santiago, 2013, pp. 175-183; y Villalón, Eduardo; León, Consuelo; y Jara, Mauricio. Jalonando Chile Austral Antártico. El Ejército en la Antártica, 1948, Instituto Geográfico Militar, Santiago, 2010, pp. 206-210. Debe no obstante considerarse que al año siguiente, el 20 de noviembre de 1949, se acordó una Declaración Tripartita chileno-argentina-británica mediante la cual, anualmente hasta el presente, los tres países se manifiestan recíprocamente que no enviarán buques de guerra al sur del paralelo $60^{\circ} \mathrm{S}$, con excepción de los movimientos logísticos regulares. Sin perjuicio de ello, en 1952 los británicos desmantelaron un refugio chileno en la isla Decepción, en las Shetland del Sur.

5 Vid. Mancilla González, Pablo. "Chile, Argentina y Gran Bretaña en el continente antártico, 1906-1961. Una aproximación a las controversias diplomáticas”. Revista de Estudios Históricos. 3 (1). 2006, s/p. [en 
Casi un año después de la interposición de las demandas, el 16 de marzo de 1956, la $\mathrm{CIJ}$ ordenó la remoción de estos asuntos del listado de causas pendientes ${ }^{6}$. En definitiva, jamás existió un pronunciamiento sobre el fondo.

No obstante ello, me ha parecido de interés recordar estos casos, con ocasión de cumplirse seis décadas de la interposición de las respectivas demandas, por dos motivos. El primero de ellos, y tal vez el más trascendente en términos globales, es que el fracaso de esta tentativa británica en 1955-1956 ayudará a crear el ambiente propicio para garantizar el éxito en la organización y ejecución del Año Geofísico Internacional 1957-1958, el que a su vez será uno de los antecedentes de las negociaciones llevadas a cabo en Washington en 1959, donde se acordó el Tratado Antártico. Como se sabe, la entrada en vigor de este acuerdo, en 1961, inauguraría una nueva etapa en la historia antártica que, entre otros logros, ha asegurado el uso pacífico de tal continente y ha suspendido las disputas soberanas al respecto ${ }^{7}$. El segundo motivo, que al menos para Chile y Argentina no debiera ser minusvalorado, es que si bien el Reino Unido no llegó a presentar una memoria en que desarrollara completamente sus argumentos, tanto en las demandas como en los intercambios epistolares de ese ańo se contienen, emanados desde fuentes oficiales, los fundamentos que los británicos consideraban tener para sustentar su reclamación soberana. El tema antártico ha tenido una gran evolución en los últimos 60 años y si en el futuro volvieran a plantearse disputas territoriales, habrían sin duda nuevas y renovadas consideraciones; pero no es menos cierto que estos argumentos británicos de 1955 volverán a estar sobre la mesa. Por lo mismo, los países entonces demandados, y no obstante el espíritu de cooperación que hoy prima en el Sistema del Tratado Antártico, no debieran ignorarlos ${ }^{8}$.

línea] <http://www.estudioshistoricos.uchile.cl> [consulta: 10 de junio del 2015]. Debe tenerse en cuenta que Estados Unidos de Norteamérica había manifestado en 1948 su parecer respecto a la inconveniencia de someter la cuestión antártica a la CIJ, "porque el prestigio de varias naciones podría verse desfavorecido", según se informaba en memorándum del Embajador de Chile (Washington) al Canciller (Santiago), Mem. E. Conf. N2185/56, 09 de agostos de 1948. DP DLA Com. V. 1948-49 MinRe., parcialmente transcrito en el artículo citado.

6 CIJ, Caso Antártica (Reino Unido c. Chile), Orden de 16 de marzo de 1956; y CIJ, Caso Antártica (Reino Unido c. Argentina), Orden de 16 de marzo de 1956, ambos en CIJ, Reports of Judgements, Advisory Opinions and Orders 1956, La Haya, 1957, pp. 15-17 y pp. 12-14, respectivamente.

$7 \quad$ El art. IV del Tratado Antártico, al tiempo que garantiza que dicho acuerdo internacional no será interpretado como una renuncia ni menoscabo a los derechos soberanos de los Estados reclamantes, dispone que los actos o actividades desarrolladas durante su vigencia no constituirán fundamentos para hacer valer, apoyar o negar reclamaciones ni para crear derechos de soberanía en la Antártica, ni tampoco se harán nuevas reclamaciones ni se ampliarán las existentes. El efecto práctico de esto es que, conforme la jerga comúnmente utilizada, desde 1961 se han "congelado" las reclamaciones y disputas soberanas sobre la Antártica.

8 Para una perspectiva general de la evolución política-jurídica de la temática Antártica y la relación entre los diversos Estados implicados, vid., entre otros, Ferrada Walker, Luis Valentín. "Iniciativa privada y estatal en la actividad antártica. Pasado, presente y futuro". Estado, sociedad y participación. XLIII Jornadas chilenas de derecho público. Santiago, Universidad de Concepción - Thomson Reuter - LegalPublishing, 2014, pp. 539-558; y Ferrada Walker, Luis Valentín. "Evolución del Sistema del Tratado Antártico: Desde su génesis 


\section{Las demandas}

Como se sabe, los territorios antárticos chileno, argentino y británico se superponen parcial o totalmente? . Por ello, la acción del Reino Unido pretendía demostrar que ambos Estados ocupaban ilegítimamente una superficie que se estimaba propia y que con sus actos violaban su soberanía. En el caso de Chile, la demanda se refería a las islas y tierras ubicadas al sur del paralelo $58^{\circ} \mathrm{S}$ entre los meridianos $53^{\circ}$ y $80^{\circ} \mathrm{O}^{10}$; y en el de Argentina, al sur del paralelo $60^{\circ} \mathrm{S}$ entre los meridianos $25^{\circ}$ y $74^{\circ} \mathrm{O}^{11}$. Las dos demandas, aunque formalmente independientes, poseen un contenido que en parte importante es idéntico, sin perjuicio de las distinciones que luego se hacen.

El mismo 4 de mayo de 1955, día de la interposición de las demandas, el Reino Unido designó como Agente al abogado Gerald G. Fitzmaurice, jurista británico de promisorio futuro ${ }^{12}$, quien suscribió las presentaciones.

No me resulta posible en este lugar entrar en un análisis pormenorizado de cada uno de los argumentos británicos consignados en las demandas (que a su vez constituyen sólo un avance de lo que se pretendía desarrollar en las memorias), ni de las eventuales respuestas que se podría dar a ellos desde la historia y el derecho, pero me parece imprescindible hacer algunos comentarios al respecto.

El primero de ellos, de alcances generales, es lo que podríamos denominar una falklandización/malvinización del tema antártico. En efecto, gran parte de las consideraciones que se hacen en las demandas son relativas a las actividades británicas en las islas Falkland/Malvinas "y sus Dependencias". Pero esto, que para el caso de Argentina pudiera

geoestratégica a sus preocupaciones ambientalistas". Revista de Derecho (18). Santiago, Universidad San Sebastián, 2012, pp. 131-151; una versión posterior del mismo artículo en Revista Quinchamalí, edición especial No 10-11. Chillán, Universidad del Biobío, 2014, pp. 118-128.

9 La reclamación de Chile carece de límite norte y se extiende entre los meridianos $53^{\circ}$ y $90^{\circ} \mathrm{O}$, hasta el Polo Sur; la de Argentina se inicia al sur del paralelo $60^{\circ} \mathrm{S}$, y se extiende entre los meridianos $25^{\circ}$ y $74^{\circ} \mathrm{O}$, hasta el Polo Sur; finalmente, la del Reino Unido se extiende al sur del paralelo $50^{\circ} \mathrm{S}$ entre los meridianos $20^{\circ} \mathrm{y}$ $50^{\circ} \mathrm{O}$, y al sur del paralelo $58^{\circ} \mathrm{S}$ entre los meridianos $50^{\circ}$ y $80^{\circ} \mathrm{O}$, sin señalar un límite sur.

Application, pp. 49-50.

Application, pp. 9-10.

12 Nota del Embajador del Reino Unido ante Países Bajos al Secretario de la CIJ, 4 de mayo de 1955, en Correspondence, p. 82. Gerald Gray Fitzmaurice (1901-1982) sería Juez de la CIJ (1960-1973) y posteriormente de la Corte Europea de Derechos Humanos (1974-1980), además de cumplir funciones como árbitro internacional. Entre otros, presidiría el tribunal arbitral que funcionó entre 1971-1977 por el asunto del Canal del Beagle, entre Chile y Argentina, en una controversia que, como se sabe, concluyó siendo resuelta mediante la Mediación Papal. Vid. MerriLls, John Graham. Judge Sir Gerald Fitzmaurice and the discipline of International Law. La Haya, Kluwer Law International, 1998, 340 p. 
tener mayor importancia ${ }^{13}$, constituye un elemento en gran parte ajeno e irrelevante para Chile. Lo que hubieren hecho o dejado de hacer los británicos en las Falkland/ Malvinas y sus islas más cercanas no tendría por qué llegar a afectar a cuanto suceda en la Antártica y sus proximidades, a una enorme distancia de aquéllas.

Por lo demás, como se reconoce en las demandas, sólo en 1908, y enmendado en 1917, se individualizaron los territorios que comprenderían tales "Dependencias"14. Aparte del archipiélago de las Falkland/Malvinas propiamente tal, en tal fecha se pretendió extender la autoridad británica a las islas Georgia del Sur, Sándwich del Sur, Orcadas del Sur, Shetlands del Sur, y a la Tierra de Graham (correspondiente a la porción norte de la península antártica $)^{15}$. Pero basta tener un mapa a la vista para advertir que se trata de situaciones muy distintas entre sí. En efecto, puede distinguirse una situación geográfica e histórica (y si se quiere jurídica) para las islas Georgia del Sur, Sándwich del Sur y Orcadas del Sur, y otra absolutamente diversa para las islas Shetlands del Sur y la parte norte de la península antártica. La controversia entre el Reino Unido y Chile sólo afectaba a estos últimos espacios, lo que hace que parte importante de los argumentos de la demanda en su contra (las múltiples y numerosas referencias a las islas Falkland/ Malvinas, Georgia del Sur, Sándwich del Sur y Orcadas del Sur) resulten en realidad impertinentes. Como se ha indicado, esta acción se restringía expresamente a la superficie al sur del paralelo $58^{\circ} \mathrm{S}$ comprendida entre los meridianos $53^{\circ}$ y $80^{\circ} \mathrm{O}$, pero ninguno de estos territorios insulares se ubican dentro de ella. Finalmente, no puede dejar de considerarse que para el año 1908, y con mayor razón para 1917, Chile no sólo llevaba largo tiempo haciendo manifestación pública de sus derechos antárticos, dictando normas y actos administrativos al respecto o incluso publicando mapas que incluían estos espacios (como el de Bertrand, de 1884; o el de Risopatrón, de 1907), y que ninguna relación tenían con lo relativo a las Falkland/Malvinas, sino que además había propiciado a partir de 1906 una serie de conversaciones diplomáticas con Argentina destinadas a

13 De hecho, como se sabe, el asunto de las Falkland/Malvinas representa un tema relevante de su política exterior; y su política antártica, hasta el presente, manifiesta esta misma falklandización/malvinización que se comenta.

14 Application, pp. 53 y 55, y pp. 13 y 15-16, respectivamente. Se trata de las Cartas Patente de 1908 y 1917, cuyo texto se acompañó como anexo, Application, pp. 39-41. La primera de ellas, en la que el Reino Unido pretende fundar sus derechos, fue promulgada como reacción a las negociaciones chileno-argentinas de 1906-1908, las cuales, como suele ocurrir en estas latitudes, fueron fallidas por enfrascarse en minucias y por falta de una visión política de largo plazo, circunstancia debidamente aprovechada por los británicos, vid. Pinochet de la Barra, Oscar. Medio siglo de recuerdos antárticos. Memorias. Santiago, Editorial Universitaria, 1994, pp. 28-35.

15 Si bien originalmente existió alguna indefinición sobre el límite sur de lo que los británicos denominaban Tierra de Graham, en definitiva tal nombre fue asignado a la parte de la península antártica al norte de la

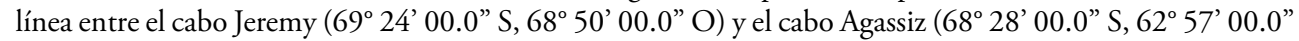
O). Vid. Scientific Committee on Antarctic Research (SCAR). Composite Gazetteer of Antarctica. [en línea] <https:/www1.data.antarctica.gov.au/aadc/gaz/scar/display_name.cfm?gaz_id=109087> [consulta: 10 de junio del 2015]. 
delimitar sus respectivos territorios en la Antártica Americana. Las demandas británicas reconocen esto último, aunque estratégicamente lo indica sin fecha y luego de referirse a las Cartas Patente de 1908, buscando dejar la impresión de que tales negociaciones de 1906-1908 serían posteriores a la manifestación británica, lo que obviamente no es asi ${ }^{16}$.

Como se ha adelantado, ambas demandas seguían un mismo esquema. Así, en los dos casos, lo primero que se hacía era circunscribir el pleito. En el caso de Chile, el Reino Unido pretendía que la controversia se habría iniciado recién el día 6 de noviembre de 1940, fecha en que se dictó el Decreto Supremo No 1.747 del Ministerio de Relaciones Exteriores, que delimita el Territorio Chileno Antártico entre los meridianos $53^{\circ}$ y $90^{\circ} \mathrm{O}$ y hasta el Polo Sur ${ }^{17}$. Se postulaba que este acto administrativo vulneraría la soberanía británica en el área, en conformidad a lo consagrado en las Cartas Patente de 1908 y 1917. En cuanto al objeto litigioso, éste sería la parte norte de la península antártica (Tierra de Graham) y las islas Shetlands del Sur ${ }^{18}$. Curiosamente, no se hacía mención alguna al sector sur de la península antártica ni menos al área continental interior, aunque claramente estaban incluidas en el decreto chileno. Incluso el mapa que se acompañó a las demandas sólo graficaba hasta el paralelo $75^{\circ} \mathrm{S}$ aproximadamente ${ }^{19}$. En el caso de Argentina, el Reino Unido consideraba que la controversia se habría iniciado en 1925, cuando ésta formuló pretensiones sobre las islas Orcadas del Sur, a lo que en 1927 agregó las islas Georgia del Sur, y en 1937 extendió a todos los territorios de las Dependencias de las islas Falkland/Malvinas. Esto fue posteriormente confirmado por la delimitación hecha en 1942 del denominado Territorio Antártico Argentino, enmendada en 1946, y según la cual éste comprendería la región al sur del paralelo $60^{\circ} \mathrm{S}$ entre los meridianos $25^{\circ}$ y $74^{\circ} \mathrm{O}$, además de las islas Georgia del Sur y Sándwich del Sur (que se ubican al norte del citado paralelo). Estimando que esto vulneraba los derechos británicos, el objeto litigioso era necesariamente más amplio que en el caso de Chile, desde que la reclamación argentina queda totalmente superpuesta a la reclamación británica ${ }^{20}$.

\footnotetext{
Application, p. 62 y p. 22, respectivamente.

Debe tenerse en cuenta que con independencia de sus efectos internacionales inmediatos, en tanto manifestación de la voluntad del Estado de Chile, y de la publicidad que se le dio en la fecha de su dictación, siendo recogido en la Memoria del Ministerio de Relaciones Exteriores de 1940 y, entre otros, en PinOcheT de la Barra, Oscar. La Antártida Chilena o Territorio Chileno Antártico. Santiago, Imprenta Universitaria, 1944, pp. 23-24, obra esta última desde donde lo recogió la demanda británica (reproduciéndolo, traducido al inglés, en Application, p. 76), él sólo sería publicado en el Diario Oficial, No 23.177, de 21 de junio de 1955. A esta fecha Chile ya contaba con varias bases de operación permanente y ejercía su autoridad en tales latitudes. Una explicación plausible sobre las razones que justificaron esta demora en publicarlo en Jara Fernández, Mauricio. "El Territorio Antártico Chileno: De la reclamación a la incorporación administrativa-política del sector polar, 1906-1956”, en León Wöppke, Consuelo y Jara Fernández, Mauricio (editores). Esbozando la historia antártica latinoamericana. Viña del Mar, Editorial LW, 2013, pp. 171-172.

Application, pp. 48-50.

9 Es el Anexo II, que se encuentra archivado al final del legajo, Vid. Correspondence, después de p. 114.

20 Application, pp. 8-11.
} 
Los siguientes cuatro apartados de ambas demandas eran idénticos, y se referían (i) al pretendido origen de los títulos británicos entre 1675 y 1843, fundados en los descubrimientos históricos y en los actos de nacionales británicos ${ }^{21}$; (ii) al presunto ejercicio de soberanía británica en el período 1843-1908 en y en relación con las Dependencias de las islas Falkland/Malvinas ${ }^{22}$; (iii) al eventual ejercicio soberano entre 1908-1938 sobre iguales territorios ${ }^{23}$; y (iv) al supuesto reconocimiento de la reclamación británica por parte de Noruega, Argentina y Chile con posterioridad a las Cartas Patente de $1908^{24}$.

En esta parte de los requerimientos, de naturaleza más bien histórica, se incurría en una serie de excesos. Entre ellos, la relevancia dada a los viajes de James Cook quien, como se sabe, en ninguno de sus tres periplos (entre 1768 y 1779) logró descubrir la Antártica, lo que llevó a creer en su época que la mítica Terra Australis era en realidad inexistente. También se contenían abusos al razonamiento jurídico, como pretender que la solicitud de autorización hecha por un particular es equivalente al reconocimiento hecho por un Estado (acto unilateral que requiere de una serie de condiciones para llegar a producir efectos jurídicos) o que cualquiera haya sido la actitud de las autoridades noruegas, ella pudiera empecer a Chile o Argentina. A ello se sumaba, al menos respecto a la demanda contra Chile, que la parte mayoritaria de estos argumentos carecía de una conexión real con los territorios efectivamente en disputa. De todos modos, hay aquí un buen resumen de la historia antártica "según la Foreign Office", que no sólo debe tenerse presente sino que debiera incentivar los estudios histórico-jurídicos sobre aquellos aspectos que exprofeso se omiten o que contradicen al relato presentado, y que son precisamente los antecedentes que por una parte debilitan la posición británica y por otra refuerzan la de los Estados que fueron demandados.

Los siguientes tres apartados diferían en las dos demandas, desde que hacían referencia a algunos hechos específicos de cada caso. Pero sus líneas generales eran en gran parte coincidentes. En aquella contra Chile, éstos se referían (i) a la proclamación en 1940 de los límites del Territorio Chileno Antártico ${ }^{25}$, omitiéndose que los derechos chilenos sobre el mismo habían sido manifestados desde principios del siglo XIX y se basaban a su vez en títulos coloniales; (ii) al rechazo por parte del Reino Unido de la delimitación chilena y a la eventual continuación del ejercicio soberano británico después de $1940^{26}$; y (iii) a la persistencia de Chile respecto a su reclamación delimitada en 1940 y su subsecuente intromisión material en los pretendidos territorios británicos, incluyendo el establecimiento de bases $^{27}$. En la demanda contra Argentina se enfatizaba en (i) el origen

\footnotetext{
Application, pp. 51-53 y pp. 11-13, respectivamente.

Application, pp. 53-55 y pp. 13-16, respectivamente.

Application, pp. 56-61 y pp. 16-21, respectivamente.

Application, pp. 61-64 y pp. 21-24, respectivamente.

Application, pp. 64-65.

Application, pp. 65-67.

Application, pp. 67-69.
} 
y desarrollo de la pretensión argentina sobre las islas y territorios de las Dependencias de las islas Falkland/Malvinas y los intentos de usurpar tales territorios a la soberanía británica $^{28}$; (ii) el rechazo por el Reino Unido a la pretensión argentina y el ejercicio continuo de soberanía británica sobre tales territorios hasta la fecha de presentación de la demanda ${ }^{29}$; y (iii) la persistencia de Argentina en sus pretensiones respecto a las Dependencias de las islas Falkland/Malvinas y su subsecuente intromisión material en las islas Orcadas del Sur y Shetlands del Sur y en la denominada Tierra de Graham ${ }^{30}$.

Los cuatro apartados finales de ambas demandas eran prácticamente idénticos. En éstos, (i) se pretendía una limitada relevancia para efectos del asunto judicial en cuestión de todos los eventos acontecidos después de 1940 en el caso de Chile, o de 1925 respecto a las islas Orcadas del Sur o de 1937 en cuanto a las islas Shetlands del Sur y la Tierra de Graham en el caso de Argentina, ya que en tales fechas se habría cristalizado la controversia jurídica y los derechos de la Partes ${ }^{31}$; (ii) se analizaban someramente los casos de la isla de Palmas (1928) $)^{32}$, de la isla Clipperton $(1931)^{33}$, sobre el estatus jurídico de Groenlandia Oriental (1933) ${ }^{34}$ y sobre los islotes de Minquiers y Ecrehos (1953) 35 , cuyas resoluciones, se pretendía, negaban valor a las reclamaciones chilena y argentina, apoyando la legitimidad de los títulos del Reino Unido ${ }^{36}$; (iii) se abordaba lo relativo a la aceptación de la jurisdicción de la CIJ para este caso $^{37}$, a lo que haré mayores alcances en el siguiente punto de este comentario; y (iv) se fijaba lo contencioso, exponiendo el Reino Unido sus peticiones concretas ${ }^{38}$.

Este último aspecto, con las adecuaciones imprescindibles debido a las diferencias geográficas entre la situación antártica de Chile y Argentina, era tratado en forma igual en ambas demandas, sintetizando la pretensión británica y sus fundamentos, y estableciendo con precisión qué era lo que el Reino Unido deseaba discutir ante la CIJ en 1955.

Se señalaba y pretendía que en razón de los descubrimientos históricos realizados por sus nacionales en la región Sub-Antártica y en la Antártica; del supuesto ejercicio de

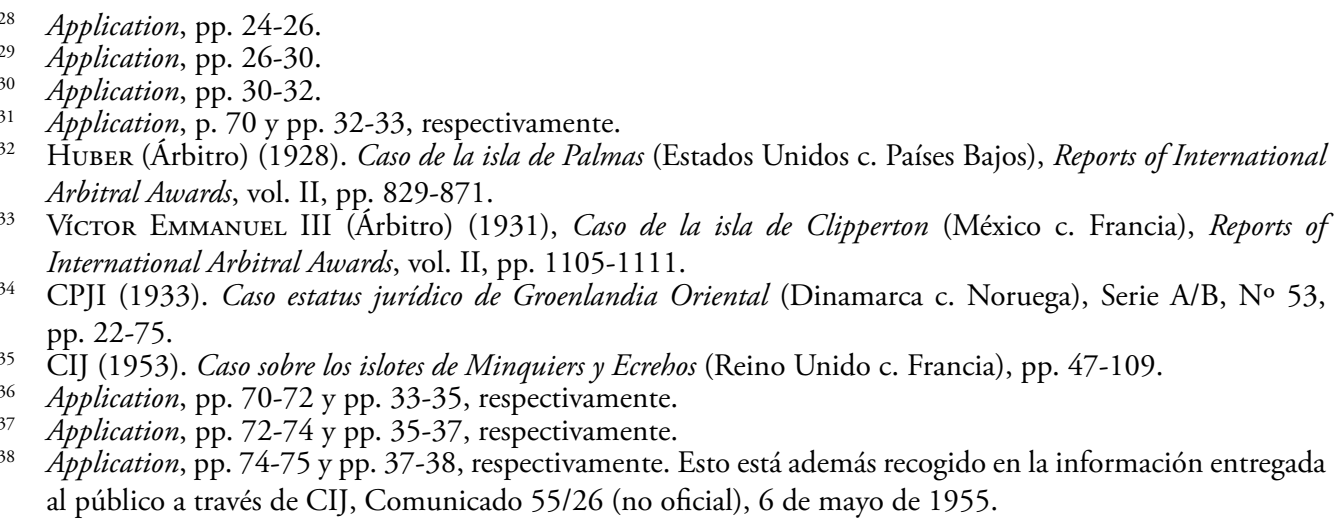


Revista Tribuna Internacional

Volumen $4 \cdot \mathrm{N}^{0} 7 \bullet 2015 \bullet$ pp. 155-172

ISSN 0719-210X (versión impresa)/ISSN 0719-482X (versión en línea)

soberanía británica desde esas fechas en adelante; de la incorporación de tales territorios en los dominios de la Corona Británica; y de su constitución formal mediante las Cartas Patente de 1908 y 1917 como una posesión británica denominada "Dependencias de las islas Falkland/Malvinas", el Reino Unido poseería, y en todo tiempo habría poseído, la soberanía sobre dichos territorios y, en particular, sobre las islas Shetlands del Sur y la Tierra de Graham para el caso de Chile y de éstas más las islas Georgia del Sur, Sándwich del Sur, Orcadas del Sur y la Tierra de Coats en el caso de Argentina. Conforme a esto, se pretendía que los títulos británicos serían, y siempre habrían sido, superiores a las reclamaciones de cualquier otro Estado, y en particular a los de las repúblicas de Chile y Argentina, respectivamente. En consecuencia, estimaba el Reino Unido que las pretensiones de estos dos países y sus actos soberanos en la Antártica serían, bajo el derecho internacional, ilegales e inválidos.

Es por esto que, en cada una de las demandas, se solicitaba a la CIJ que declarara (i) que el Reino Unido, frente a Chile o Argentina, respectivamente, poseía, y en todo tiempo había poseído, títulos de soberanía válidos y jurídicamente subsistentes sobre los territorios en disputa; (ii) que las reclamaciones chilena y argentina, así como sus respectivas intromisiones y actos soberanos en tales territorios o en relación a los mismos eran ilegales e inválidos bajo el derecho internacional; y (iii) que las repúblicas de Chile y Argentina, respectivamente, estaban obligadas a respetar la soberanía británica sobre dichos territorios, a cesar sus pretensiones de ejercer soberanía allí o en relación con ellos y, si así lo solicitaba el Reino Unido, a retirar de esos lugares a toda o cualquiera persona o equipamiento de su nacionalidad.

\section{Tramitación}

El requerimiento británico fue notificado a Chile y Argentina el 6 de mayo de 1955, siendo también comunicado a los Estados miembros de las Naciones Unidas a través del Secretario General de tal organización y a aquellos Estados que sin ser miembros de ella estuvieran habilitados para intervenir ante la $\mathrm{CIJ}^{39}$.

El Reino Unido tenía en cuenta que ni Chile ni Argentina habían aceptado la jurisdicción obligatoria de la CIJ conforme al art. 36.2 de su estatuto, ni le habían reconocido especialmente jurisdicción para este caso. Por ello, la posibilidad de que la CIJ conociera de estas materias se basaba en el art. 36.1 del estatuto, en particular en aquello de que "la competencia de la Corte se extiende a todos los litigios que las Partes le sometan".

39 Diversas notas del Secretario Adjunto de la CIJ a diferentes destinatarios, todas de 6 de mayo de 1955, en Correspondence, pp. 82-86. 
También tenía presente que desde fines de 1947 había intentado infructuosamente convencerlos de llevar esta controversia a arbitraje o arreglo judicial. A pesar de ello, y ya que cada uno de los Estados demandados "ha expresado frecuentemente su adhesión a los principios del arreglo judicial de las controversias internacionales, está, sin embargo, jurídicamente calificado para dar jurisdicción a la Corte en este caso... [y] puede tomar los pasos necesarios para tal fin”. Es decir, los británicos partían de la base que la competencia de la CIJ quedaba condicionada a que Chile y Argentina le reconocieran jurisdicción para este caso en particular ${ }^{40}$. La tramitación ante la CIJ, que se prolongaría por casi un ańo, se centró en este punto.

Tras ser notificado, el Embajador de Chile ante los Países Bajos, Luis Renard Valenzuela, solicitó al Secretario Adjunto de la CIJ que, conforme a las instrucciones de su Gobierno, todas las comunicaciones al respecto fueran despachadas directamente a Santiago ${ }^{41}$. En los días siguientes se remitieron copias certificadas de las demandas a los ministerios de relaciones exteriores de Chile y Argentina, al Agente del Reino Unido, a cada uno de los en ese entonces 73 Estados miembros de las Naciones Unidas diversos a los tres litigantes, a la Secretaría de la misma y también a los Estados no-miembros de tal organización. Llama la atención y da una seńal sobre el interés que despertaba el caso el que, además de haberse enviado copia de la demanda a cada uno de los citados Estados, se remitieran a la Secretaría General de las Naciones Unidas otras 75 copias certificadas y 300 copias simples para ser distribuidas entre los interesados ${ }^{42}$.

El 15 de julio de 1955, el Embajador Renard le envió una nota al Secretario de la CIJ en la que, respondiendo a aquella mediante la cual se notificó la demanda, manifestaba que el Estado de Chile rechazaba la jurisdicción de la CIJ para conocer acerca de cualquier asunto referido al Territorio Chileno Antártico, sobre el cual se ejercía soberanía de forma completa y absoluta. Esto había sido de hecho reafirmado y comunicado directamente al Reino Unido mediante una nota remitida a su Embajador en Santiago con fecha 4 de mayo de 1955, el mismo día de la interposición de la demanda, como se advertía expresamente ${ }^{43}$.

En dicha nota, la cual se transcribía, se daba respuesta a una anterior comunicación británica de 21 de diciembre de 1954, en la que se había propuesto someter la cuestión antártica chilena-argentina-británica ante la $\mathrm{CIJ}$ o, en su defecto, ante un tribunal arbitral ad-hoc. Se había advertido allí que si Chile no aceptaba esta propuesta, el Reino Unido se sentiría libre de emplear los recursos y medios que les franqueaba el orden jurídico in-

\footnotetext{
Application, pp. $72-74$ y pp. 35-37, respectivamente.

41 Nota del Embajador de Chile al Secretario Adjunto de la CIJ, 17 de mayo de 1955, en Correspondence, p. 86.

42 Diversas notas del Secretario de la CIJ a diferentes destinatarios, de 23 y 26 de mayo de 1955, en Correspondence, pp. 86-89.

43 Nota del Embajador de Chile al Secretario de la CIJ, 15 de julio de 1955, en Correspondence, p. 94.
} 
ternacional y de obtener de la CIJ el reconocimiento de sus derechos. Ante esta amenaza de concurrir unilateralmente ante la CIJ, Chile había manifestado que no obstante su larga tradición de respeto al principio de sometimiento a los medios de solución pacífica de controversias, en este caso resultaba imposible aceptar la jurisdicción de la CIJ sobre un territorio respecto al cual se ejercía una soberanía plena en virtud de títulos incontestables de carácter jurídico, político, histórico, geográfico, diplomático y administrativo. A mayor abundamiento, siendo Chile parte del Tratado Interamericano de Asistencia Recíproca, TIAR (1947), el que expresamente comprendía la Antártica Americana, resultaba absolutamente imposible aceptar la pretensión de un Estado extra-continental de someter a arreglo judicial o arbitral la soberanía de un territorio declarado esencial para la defensa y la seguridad americana. Además, la reclamación británica afectaba también a Argentina, con la cual Chile estaba ligado mediante una declaración conjunta (1948) en que ambos Estados se habían comprometido a defender jurídicamente el territorio comprendido entre los meridianos $25^{\circ}$ y $90^{\circ} \mathrm{O}$, sobre el que se habían reconocido recíprocamente derechos incontrastables de soberanía. Todo esto llevaba, desde luego, a formular expresas reservas sobre la fuerza jurídica que pudieran tener las Cartas Patente de 1908 y 1917 en que el Reino Unido fundaba sus pretensiones ${ }^{44}$.

La nota de 4 de mayo de 1955 continuaba seńalando que siendo imposible para Chile aceptar la propuesta del Reino Unido de someter este asunto ante la CIJ, se estimaba de provecho para toda la humanidad y valioso para el desarrollo de la ciencia el propender a la negociación de un tratado internacional entre los países con verdaderos intereses en la Antártica. Éste, con una duración limitada y sin significar un reconocimiento ni modificación de la legítima posición jurídica de las Partes, podría promover una cooperación permanente y amigable que permitiera la realización de exploraciones e investigación científica. El respeto recíproco de Chile y el Reino Unido en la Antártica haría posible la cooperación y coexistencia, y evitaría una fricción en una histórica y muy buena relación que se deseaba mantener ${ }^{45}$. He aquí una reiteración de las ideas ya expuestas en 1948 por Julio Escudero en las denominadas conversaciones EscuderoGreen, que constituyeron una anticipación del régimen que vendría a crear en 1959 el Tratado Antártico ${ }^{46}$. La génesis y negociación de este acuerdo internacional es sin duda de una mayor complejidad ${ }^{47}$, pero es destacable que las autoridades chilenas propusieran al Reino Unido, como remedio a la controversia planteada, una idea que, con todos sus matices, estaría en línea con la solución que se alcanzaría en definitiva.

\footnotetext{
Nota del Embajador de Chile al Secretario de la CIJ, 15 de julio de 1955, en Correspondence, pp. 94-95. Nota del Embajador de Chile al Secretario de la CIJ, 15 de julio de 1955, en Correspondence, pp. 95-96.

Sobre el planteamiento de Escudero, vid. Pinochet de la Barra, Medio siglo..., op.cit., pp. 73 y 76.

Entre la abundante literatura al respecto, vid. DodDs, Klaus. "La administración del continente polar: Los orígenes geopolíticos del Tratado Antártico de 1959”. Istor, (39), México D.F., 2009, pp. 27-49; y BERGUÑo Barnes, Jorge. "Historia intelectual del Tratado Antártico". Boletín Antártico, 19 (1), Santiago, 2000, pp. 2-12.
} 
La nota enviada al Embajador británico en Santiago concluía poniendo en duda que la CIJ pudiera entrar a conocer este asunto por la sola petición unilateral del Reino Unido, haciéndose desde ya reservas respecto a su competencia para fallar sobre cuestiones de soberanía antártica sin el consentimiento expreso del Estado de Chile ${ }^{48}$.

En virtud de todo lo anterior, y al tenor de la nota transcrita, el Embajador Renard le manifestaba al Secretario de la CIJ que se estimaba inútil entrar a discutir los argumentos británicos, fundados únicamente en el descubrimiento, en el ejercicio de actos administrativos sin sustento jurídico alguno y en la promulgación de cartas patente referidas a un territorio respecto al cual Chile era soberano en virtud de títulos jurídicos, políticos, históricos, geográficos, diplomáticos y administrativos incontrarrestables, y anteriores a aquéllas ${ }^{49}$.

El 1 de agosto de 1955, el Embajador de Argentina ante los Países Bajos, Natalio Carvajal Palacios, le envió dos notas al Secretario de la CIJ. En la primera de ellas, y dando respuesta a la notificación de 6 de mayo de 1955, se transcribía una nota remitida a la CIJ por el Ministro de Relaciones Exteriores y Culto argentino. Allí se manifestaba que ya se había comunicado al Embajador del Reino Unido en Buenos Aires que no se aceptaría que las cuestiones sobre la soberanía antártica argentina fueran sometidas a la decisión de un tribunal internacional o a arbitraje, lo que se reiteraba ahora al Secretario de la CIJ con el expreso rechazo a que ese tribunal pudiera ejercer jurisdicción en estos asuntos. El Gobierno argentino se veía obligado a declarar como principio fundamental el que la soberanía territorial no podía ser sometida a discusión ni puesta en duda, sobre todo cuando ella se basaba en derechos incuestionables y en títulos que derivaban y se sustentaban en los modos legítimos de adquirir el dominio territorial y en una posesión efectiva, continua y pacífica. En definitiva, por este y otros motivos oportunamente expresados, resultaba imposible para Argentina aceptar la jurisdicción de la CIJ ${ }^{50}$.

En la segunda nota del Embajador Carvajal se transcribía la referida comunicación al Embajador del Reino Unido en Buenos Aires, de 4 de mayo de 1955. Es decir, de la misma fecha de interposición de la demanda y de aquella otra nota enviada por Chile en igual sentido al representante británico en Santiago. A través de ella se daba respuesta a una proposición de 21 de diciembre de 1954 de buscar un medio pacífico de solución de controversias para la cuestión antártica, equivalente a lo propuesto a Chile, según ya se ha comentado. El Gobierno trasandino partía por afirmar que las Cartas Patente de 1908 y 1917 en que el Reino Unido pretendía sustentar sus derechos eran, desde la perspectiva del derecho internacional, totalmente ineficaces como fundamentos de

\footnotetext{
Nota del Embajador de Chile al Secretario de la CIJ, 15 de julio de 1955, en Correspondence, p. 96. Nota del Embajador de Chile al Secretario de la CIJ, 15 de julio de 1955, en Correspondence, p. 96.

Nota del Embajador de Argentina al Secretario de la CIJ, 1 de agosto de 1955, en Correspondence, pp. 89-90.
} 
Revista Tribuna Internacional

Volumen $4 \cdot \mathrm{N}^{0} 7 \bullet 2015 \bullet$ pp. 155-172

ISSN 0719-210X (versión impresa)/ISSN 0719-482X (versión en línea)

soberanía, al ser actos exclusivamente unilaterales que no contaban con la conformidad de Argentina. Por el contrario, siendo las islas Falkland/Malvinas de soberanía argentina y habiendo sido ellas usurpadas por el Reino Unido, de su proyección no podían nacer derechos antárticos en su favor. Los Estados no tenían ninguna obligación de someter a tribunales extranjeros la legitimidad de sus títulos soberanos, ni Argentina tenía la intención de hacerlo. Se abordaban a continuación otras consideraciones similares a las ya vistas respecto a los efectos del TIAR (1947) y la Declaración Conjunta chilenoargentina (1948), concluyendo que no se podía aceptar la pretensión del Reino Unido de remitir estos asuntos a la CIJ ni a ningún otro tribunal internacional o arbitral ${ }^{51}$.

El 3 de agosto de 1955, el Secretario de la CIJ remitió las comunicaciones de Chile y Argentina al Agente Fitzmaurice, manifestando ya habérselas entregado a los jueces de la $\mathrm{CIJ}^{52}$.

Al finalizar ese mes, el Agente británico dio respuesta al Secretario de la CIJ, abordando en forma conjunta las referidas comunicaciones. Manifestó que su país tenía conciencia de que la competencia de la CIJ estaba condicionada a la aceptación de Chile y Argentina, pero lamentaba la actitud tomada por estos Estados, ya que estimaba que la CIJ podría haber provisto de una solución larga y pacientemente buscada por el Reino Unido a una disputa cuya continuación perturbaría una relación que de otro modo habría sido buena. Aun sabiendo que anteriormente estos países habían manifestado su rechazo a someter la cuestión antártica a un tribunal internacional o al arbitraje, se había esperado que hubieran podido reconsiderar su postura ante una demanda específica ante la CIJ, en que había un juez argentino ${ }^{53}$ y por largos ańos había habido uno chileno ${ }^{54}$. Le parecía que este era un caso que requería una solución judicial, ya que continuar con la

51 Nota del Embajador de Argentina al Secretario de la CIJ, 1 de agosto de 1955, en Correspondence, pp. 91-93.

52 Notas del Secretario de la CIJ al Agente británico, 3 de agosto de 1955, en Correspondence, p. 97. Valga la oportunidad para dejar consignado que a esa fecha presidía la CIJ el estadounidense Green H. Hackworth, ella estaba además integrada por el chino Hsu Mo, el salvadoreño José Gustavo Guerrero, el canadiense John Erskine Read, el yugoslavo Milovan Zoričić, el noruego Helge Klaestad, el francés Jules Basdevant, el egipcio Abdel Hamid Badawi, el polaco Bohdan Winiarski, el uruguayo Enrique c. Armand-Ugon, el soviético Feodor Ivanovitch Kojevnikov, el paquistaní Muhammad Zafrulla Khan, el británico Hersch Lauterpacht, el mexicano Roberto Córdova y el argentino Lucio Manuel Moreno Quintana. Esto es, de los quince jueces había cuatro que eran nacionales de Estados reclamantes de soberanía territorial en la Antártica, incluyendo a un británico y a un argentino; había asimismo un juez nacional de cada una de las dos superpotencias de la Guerra Fría más uno nacional de China; y seis de los jueces, contando un norteamericano y un canadiense, pertenecían al sistema interamericano. Sin siquiera entrar a considerar los distintos sistemas jurídicos que representaban cada uno de los quince jueces, es evidente que una disputa de soberanía territorial antártica habría tenido una cantidad impresionante de consideraciones políticas implícitas.

53 Como se ha visto, a la fecha de la interposición de la demanda era Juez de la CIJ el jurista argentino Lucio Manuel Moreno Quintana (1955-1964).

54 Acaba de dejar su cargo de Juez de la CIJ, tras ejercerlo por casi una década, el chileno Alejandro Álvarez (1946-1955). 
pretendida intromisión en el territorio antártico británico y negarse al mismo tiempo a cada una de las propuestas de solución pacífica de controversias era una actitud difícil de conciliar con el texto y espíritu de la Carta de las Naciones Unidas a la que tanto Chile como Argentina estaban obligados ${ }^{55}$.

Sin cuestionar el derecho que estos países tenían de negar la competencia a la CIJ, al Reino Unido le resultaba imposible reconocer la validez de las razones aducidas para ello. Se estimaba, en este sentido, que no existía un principio jurídico según el cual los títulos soberanos no pudieran ser sometidos al conocimiento de la CIJ. Por el contrario, existían múltiples ejemplos en que diversos tribunales habían resuelto cuestiones de soberanía territorial, como en los casos de los islotes de Minquiers y Ecrehos (1953) y sobre el estatus jurídico de Groenlandia Oriental (1933), este último referido a una región de gran similitud con la que ahora se disputaba. Por ello, no podía aceptarse que este asunto no pudiera resolverse por medios jurisdiccionales o que fuera inapropiado someterlo a la $\mathrm{CIJ}^{56}$.

Se había sugerido, asimismo, que los títulos de Chile y Argentina serían tan auto-evidentes que no requerían ninguna determinación judicial. El Reino Unido no podía estar de acuerdo con ello, no sólo porque tales títulos se enfrentaban a los que se habían detallado en las demandas y que sustentaban la soberanía británica, sino también porque Chile y Argentina reclamaban un mismo territorio en función de idénticos fundamentos. Aun sin tener en cuenta los títulos británicos, no era posible considerar simultáneamente las reclamaciones de Chile y de Argentina como auto-evidentes. El plantear, por otra parte, que tales reclamaciones no requerían ninguna investigación ya que las solas consideraciones históricas o geográficas eran suficientes -punto de vista que no lograría explicar cómo ambas reclamaciones, basadas en iguales fundamentos, podían ser válidas respecto a un mismo territorio- no podía ser aceptado por el Reino Unido. En principio, porque tal como habrían resuelto los tribunales internacionales, debía darse preeminencia al ejercicio concreto y continuo de soberanía efectiva por sobre otros títulos, pero con mayor razón todavía porque no podía aceptarse una sucesión histórica de España respecto a territorios que jamás habrían sido españoles y ni siquiera habría sido conocida su existencia hasta su descubrimiento por exploradores británicos (argumento que, valga la pena apuntar, es falaz, ya que constan las repetidas menciones a la Terra Australis en los antiguos títulos coloniales americanos, así como los intentos efectuados por la monarquía castellana a fin de expandir su dominio hacia las latitudes polares). En cuanto a los factores geográficos, aunque ellos pudieran ser admitidos en general, el Reino Unido estimaba que en este caso no resultaban aplicables por la enorme distancia entre los territorios metropolitanos de Chile y Argentina y los territorios

55 Nota del Agente británico al Secretario de la CIJ, 31 de agosto de 1955, en Correspondence, pp. 97-98.

56 Nota del Agente británico al Secretario de la CIJ, 31 de agosto de 1955, en Correspondence, p. 98. 
Revista Tribuna Internacional

Volumen $4 \cdot \mathrm{N}^{0} 7 \bullet 2015 \bullet$ pp. 155-172

ISSN 0719-210X (versión impresa)/ISSN 0719-482X (versión en línea)

antárticos (la que, no está de más resaltar, es en cualquier caso mucho menor que la que hay desde las islas Falkland/Malvinas y para qué decir desde las islas de la Gran Bretaña, en Europa). En apoyo de estos argumentos se citaba el caso sobre los islotes de Minquiers y Ecrehos (1953), en que la CIJ había dado preeminencia a la posesión efectiva por sobre ciertos antecedentes que vendrían de la Edad Media, y el caso de la isla de Palmas (1928), donde el árbitro Huber había negado que existiera una regla de derecho internacional que diera mayor valor como título territorial a la contigüidad que a la realización concreta de actos soberanos ${ }^{57}$.

El Agente Fitzmaurice destacaba que las actividades realizadas por Chile y Argentina en la Antártica, y los actos de posesión en que fundaban sus reclamaciones, eran en su mayoría muy recientes y posteriores a las fechas críticas en que se pretendía que habrían cristalizado las controversias. Como se había destacado en las demandas, tales actos habrían sido ejecutados no sólo para mejorar la posición jurídica de las partes, sino que con el expreso propósito de dar sustento a unas reclamaciones que se estimaban carentes de fundamentos previos y que no podrían haberlos tenido pues ello habría significado vulnerar los títulos británicos, haciendo que cualquiera de tales demostraciones soberanas fuera ilegal y prohibida. De acuerdo a lo que se pretendía como un principio internacional sustentado en los casos de la isla de Palmas (1928), de la Groenlandia Oriental (1933), y de los islotes de Minquiers y Ecrehos (1953), las actividades de Chile y Argentina, opinaba el Reino Unido, no podían llevar al establecimiento de un título ni podían ser tenidas en cuenta por un tribunal internacional. A mayor abundamiento, esto debería ser también aplicado a cualquier acto posterior a la remisión de estos casos a la CIJ, aunque los Estados demandados no le hubieran reconocido jurisdicción y, aún más, a cualquier acto posterior al establecimiento del título británico o al menos posterior a la fecha en que se pretendía haberse cristalizado la controversia, en 1940 para Chile y en 1925 o 1937 para Argentina. Todos los actos posteriores a estas fechas efectuados por tales países en la Antártica serían, según el Reino Unido, totalmente nulos y prohibidos, y no podían servir ni para probar ni para fundar sus títulos. En definitiva, el Estado demandante opinaba que la negativa a conferir jurisdicción a la CIJ no podía significar que Chile y Argentina mejoraran su posición jurídica. Finalmente, el Agente Fitzmaurice advertía, con un leve tono de amenaza, que habiendo agotado todos los medios pacíficos, el Reino Unido no era responsable de las consecuencias que pudieran seguirse de la negativa de Chile y Argentina de concurrir a la CIJ y de su persistencia en la intromisión ilegal en territorio británico ${ }^{58}$.

57 Nota del Agente británico al Secretario de la CIJ, 31 de agosto de 1955, en Correspondence, pp. 98-99.

58 Nota del Agente británico al Secretario de la CIJ, 31 de agosto de 1955, en Correspondence, p. 100. 
Un par de días después, esta comunicación fue remitida a los respectivos ministerios de relaciones exteriores de ambos Estados demandados ${ }^{59}$. Frente a ello, el Embajador Renard manifestó al Secretario de la CJI que no se haría ningún comentario al respecto, especialmente por cuanto, conforme a lo manifestado en nota de 15 de julio de 1955, Chile había decidido, por las razones allí explicadas, no aceptar la jurisdicción de la CIJ. No siéndole obligatorio hacerlo, y teniendo en cuenta lo dispuesto en el art. 36 del estatuto, la CIJ no podía intervenir en estas materias. Tampoco se pretendía polemizar con el Agente británico sobre el derecho soberano que tenía Chile de aceptar o no la jurisdicción opcional de la CIJ ${ }^{60}$.

Tras cinco meses de inactividad procesal, el 16 de marzo de 1956 la CIJ tendría en cuenta que su jurisdicción no había sido aceptada ni por Chile ni por Argentina de modo que la habilitara para conocer de las demandas interpuestas, por lo cual ella no tenía más que hacer a estos respectos, ordenando que los casos fueran removidos de la lista de asuntos pendientes ${ }^{61}$. Como expresara con elegancia la CIJ en su comunicado público, teniendo en consideración que las demandas habían sido notificadas el 6 de mayo de 1955, "de las respuestas recibidas desde entonces de ambos gobiernos, es claro que ellos no están preparados para aceptar la jurisdicción de la Corte en estos casos” ${ }^{62}$.

En los días siguientes se notificó la decisión adoptada a los Estados implicados, a la Secretaría General de las Naciones Unidas y a los Estados partes y no-partes del Estatuto de la $\mathrm{CIJ}^{63}$.

La necesidad de "remover los casos de la lista" se presentó en casos como éstos hasta la modificación del Reglamento de la CIJ en 1978, ya que junto con interponerse una demanda en contra de un Estado que todavía no hubiera aceptado la jurisdicción de la CIJ, "invitándolo a hacerlo", se ingresaba el caso de inmediato a la lista general. Aparecía así el Estado demandado como parte en una controversia judicial de la cual, eventualmente, si rechazaba la "invitación” a conferir jurisdicción a la CIJ, jamás llegaría a serlo. Al modificarse el reglamento se incluyó el actual art. 38.5, que dispone que ante la interposición de una acción en contra de un Estado que no hubiera aceptado aún la jurisdicción de la CIJ, la Secretaría se limitará a transmitirle la demanda, pero sin

59 Notas del Secretario de la CIJ a los ministros de relaciones exteriores de Chile y Argentina, 3 de septiembre de 1955, en Correspondence, p. 101.

60 Nota del Embajador de Chile al Secretario de la CIJ, 10 de octubre de 1955, en Correspondence, pp. 101-102; transmitida por nota del Secretario de la CIJ al Agente británico, 13 de octubre de 1955, en Correspondence, p. 102.

61 CIJ, Caso Antártica (Reino Unido c. Chile), Orden de 16 de marzo de 1956; y CIJ, Caso Antártica (Reino Unido c. Argentina), Orden de 16 de marzo de 1956, ambos en CIJ, Reports of Judgements, Advisory Opinions and Orders 1956, La Haya, 1957, pp. 15-17 y pp. 12-14, respectivamente.

62 CIJ, Comunicado 56/5 (no oficial), 17 de marzo de 1956.

63 Distintas notas del Secretario de la CIJ a diversos destinatarios, 16 al 23 de marzo de 1956, en Correspondence, pp. 102-105. 
inscribir el caso en la lista general ni efectuar acto alguno de procedimiento en tanto tal jurisdicción no haya sido aceptada ${ }^{64}$.

\section{Algunas conclusiones}

Ciertamente resulta imposible saber con certeza qué hubiera acontecido si las demandas del Reino Unido contra Chile y contra Argentina hubieran seguido su curso. Pero aún sin llegar a plantear una ucronía es posible imaginar que tal pleito habría constituido un escollo para las iniciativas antárticas que en esos mismos momentos se gestaban.

En el mes de julio de 1955 se desarrolló en París la primera reunión preparatoria para lo que serían las actividades del Año Geofísico Internacional 1957-1958 en la Antártica ${ }^{65}$. Esta iniciativa científica, pero colmada de facetas políticas, será a su vez la que permitirá el acercamiento requerido para que en 1959 se reúna la Conferencia de Washington, cuyo resultado será el Tratado Antártico, en vigor desde 1961. Es altamente improbable que todo esto hubiera acontecido, al menos del mismo modo, con un juicio pendiente ante el tribunal de La Haya. Por el contrario, y si bien tal acuerdo internacional no solucionó las disputas soberanas sino que únicamente las pospuso, su ejecución práctica ha dado lugar a un sistema internacional de co-gobierno antártico ampliamente exitoso, que ha permitido hasta la fecha sustituir los conceptos más tradicionales de soberanía territorial. Además, ha garantizado el uso pacífico de ese enorme continente y el desarrollo de la ciencia, propendiendo desde la década de 1970 a la conservación de sus recursos y desde los años de 1990 a la protección de su medioambiente. Este resultado, al menos por ahora, parece inmensamente mejor que el haber aclarado los límites antárticos entre Chile, Argentina y el Reino Unido.

$64 \mathrm{Al}$ respecto, vid. Quintana, Juan José. "La Impugnación de la Competencia en Asuntos Contenciosos ante la Corte Internacional de Justicia". Anuario Colombiano de Derecho Internacional, ACDI. Año 1, No 1. Bogotá, 2008, pp. 14-15. Esta misma situación de tener que "remover" un caso de la lista sucedió además respecto a CIJ (1954). Asunto sobre el tratamiento en Hungría de aeronave y tripulación de los Estados Unidos de América (Estados Unidos c. Hungría) (Estados Unidos c. Unión Soviética); CIJ (1955). Asunto sobre incidente aéreo de 7 de octubre de 1952 (Estados Unidos c. Unión Soviética); CIJ (1955). Asunto sobre incidente aéreo de 10 de marzo de 1953 (Estados Unidos c. Checoslovaquia); CIJ (1958). Asunto sobre incidente aéreo de 4 de septiembre de 1954 (Estados Unidos c. Unión Soviética); y, CIJ (1959). Asunto sobre incidente aéreo de 7 de noviembre de 1954 (Estados Unidos c. Unión Soviética).

65 Habían existido dos reuniones previas, en 1953 y 1954, de las que Chile sólo participó en la segunda, pero cuyo objeto había sido más amplio. La primera reunión preparatoria referida propiamente a la Antártica fue la de 1955. Vid. Mancilla González, Pablo. "Chile y el proceso preparatorio para el Año Geofísico Internacional, 1950-1957”, en Jara Fernández, Mauricio y Mancilla González, Pablo (editores). El Año Geofísico Internacional en la perspectiva histórica chilena, 1954-1958. Valparaíso, Editorial Puntángeles - Universidad de Playa Ancha, 2012, pp. 40-43. 
También debe resaltarse, como un hito positivo, la coordinación y actuación conjunta de Chile y Argentina en los hechos relativos a esta cuasi-disputa judicial. La relación antártica chileno-argentina no ha estado exenta de complejidades a través de los años, pero con el paso del tiempo se han logrado ciertos entendimientos a los que en ocasiones se han sumado incluso otros Estados sudamericanos partícipes en el Sistema del Tratado Antártico. Esto ha dado lugar a una potente posición regional que debiera ser promovida.

Respecto a Chile, la acción del Reino Unido también resultó de gran valor, ya que reactivó la política antártica nacional. El año 1955 se concluyeron las formalidades relativas al decreto supremo de 1940, que había fijado los límites del Territorio Chileno Antártico; se aprobó por el Congreso Nacional, se promulgó y se publicó la Ley No 11.846, vigente hasta el presente, que dispuso que correspondería al Intendente de Magallanes (hoy de la Región de Magallanes y Antártica Chilena) el conocimiento y resolución de los asuntos administrativos referentes a la Antártica Chilena o Territorio Chileno Antártico y que dispuso dictar un estatuto especial al respecto; tal norma, el Decreto Supremo No 298 de 1956 del Ministerio de Relaciones Exteriores, también vigente hasta el presente, constituye la regulación nacional más completa sobre materias antárticas. En definitiva, producto de la reacción pública provocada por la demanda británica, el Gobierno del Presidente Ibáńez se vio en la necesidad de desarrollar y explicitar una política antártica. Ella fue presentada ante la Cámara de Diputados el 18 de abril de 1956 y fijaba metas y objetivos relativos a (i) la promoción de la conciencia antártica nacional; (ii) el incremento de los actos de ocupación y administración del Territorio Chileno Antártico, a través de la instalación de bases, la ejecución de expediciones y el desarrollo de actividades científicas; (iii) la participación activa de Chile en el Año Geofísico Internacional 1957-1958; (iv) la promulgación de las normas jurídicas necesarias para una mejor administración del territorio antártico; (v) el mandato perentorio y bajo sanción de que todos los mapas nacionales incluyeran en forma íntegra el Territorio Chileno Antártico; y (vi) la difusión de la política antártica a través de los planteles educacionales ${ }^{66}$.

La protección y administración de la Antártica es uno de los grandes desafíos del s. XXI, en especial para aquellos países, como Chile, que poseen una íntima vinculación con tal continente. El comentario sobre estos casos judiciales debiera servir como un incentivo para continuar reflexionando sobre el modo de dar cumplimiento al primero y más permanente de los objetivos de la Política Antártica Nacional: proteger y fortalecer los derechos antárticos de Chile, en el marco del Tratado Antártico y a través de su fiel cumplimiento ${ }^{67}$.

66 Congreso Nacional de Chile. Sesiones de la Honorable Cámara de Diputados. Sesión 12, de 18 de abril de 1956, pp. 568-584.

67 Decreto Supremo No 429 del 2000, del Ministerio de Relaciones Exteriores. 